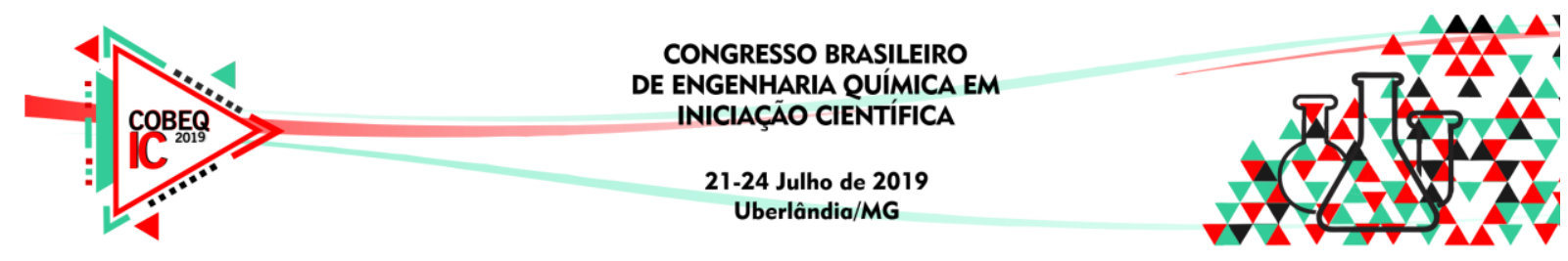

\title{
AVALIAÇÃO DA SIMULAÇÃO DO PROCESSO DE PRODUÇÃO DE RAÇÃO ANIMAL A PARTIR DO RESÍDUO DE MAMÃO E LARANJA
}

\author{
G. M. ANDRADE ${ }^{1}$, E. B. MARRA ${ }^{1}$, W. S. CHIMATTI ${ }^{1}$, M. F. MENDES ${ }^{2}$, C. S. S. \\ PEREIRA $^{1}$ \\ ${ }^{1}$ Universidade de Vassouras, Engenharia Química \\ ${ }^{2}$ Universidade Federal Rural do Rio de Janeiro, Engenharia Química \\ E-mail para contato: geisianemoraes@gmail.com
}

\begin{abstract}
RESUMO - O Brasil situa-se em um dos maiores faturamentos de produtos para animais domésticos e isso inclui uma fração do setor alimentício. Ocasionando o aumento da produção de ração, despertando o interesse dos fabricantes. Novas fontes alternativas naturais estão sendo estudadas. Há um grande consumo de sucos e polpas no Brasil, gerando em média, $40 \%$ de resíduos. O processo produtivo de frutas cristalizadas estudado neste trabalho possuiu $15 \%$ de resíduo em 5.000 toneladas produzidas por ano. Sem destino, essa biomassa ocasiona impactos ambientais e até custo com seu descarte. Primeiramente foi comparada uma tabela com parâmetros nutricionais de legislação vigente do Ministério da Agricultura, Pecuária e Abastecimento e análise feita em laboratório credenciado, relacionando os resultados com a alimentação do processo em quantidade e porcentagem. Resultando em uma análise de custo benefício da biomassa na composição do processo de ração para cães. A partir desse cenário, o objetivo deste trabalho visa o reaproveitamento da biomassa proveniente do processo de frutas cristalizadas para a produção de ração para animais domésticos, a fim de reduzir impactos ambientais e estabelecer lucro através do subproduto. O processo foi simulado utilizando o simulador de processos SuperPro Designer ${ }^{\circledR}$.
\end{abstract}

\section{INTRODUÇÃO}

O Brasil é o $3^{\circ}$ maior em faturamento no setor de produtos para animais domésticos, isso inclui o segmento de alimentação onde, 20,3 bilhões de reais no ano de 2017, 68,6\% é do segmento de alimentação animal (ABINPET, 2018). Assim vem despertando interesse de fabricantes, que tem como objetivo fornecer produtos com nutrientes e promovendo uma alimentação saudável aos animais. Estão sendo estudadas novas fontes alternativas naturais que são ricas em minerais, ácidos graxos e proteínas (Lirio, 2018).

Em 2004, o Instituto Brasileiro de Frutas (IBRAF) fez uma estimativa de 350 milhões de litros a produção/consumo de sucos e polpas à base de frutas no Brasil. Este processamento gera cerca de 40\% dos resíduos agroindustriais (Abud e Narain, 2009). 


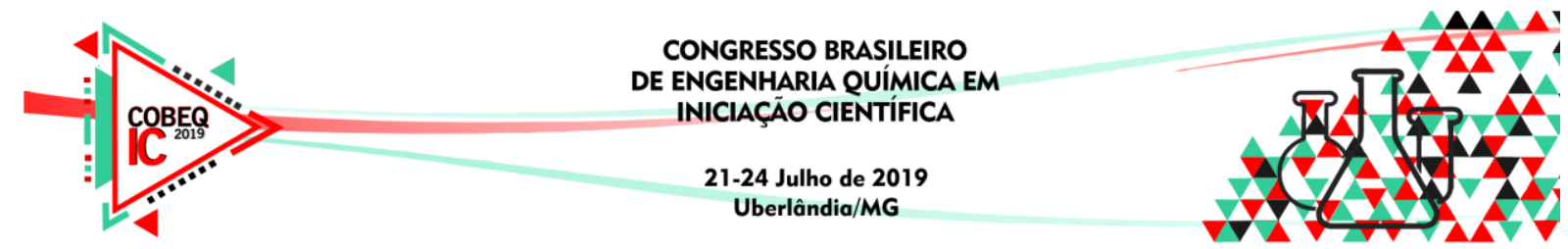

As matérias orgânicas geradas como resíduo nas empresas representam uma quantidade significativa de descarte anual, o que pode impactar o meio ambiente, tornando áreas propicia ao desenvolvimento de insetos e pragas (Souza et al., 2011).

O processo de produção de frutas cristalizadas gera um resíduo que deve ser tratado e destinado de forma correta. Como não há um tratamento específico, os resíduos orgânicos gerados pela empresa em estudo representam uma quantidade significativa de resíduo descartado anualmente, impactando diretamente o meio ambiente. A proposta de reutilização dos resíduos orgânicos para o processamento de novos produtos contribui para a minimização dos impactos ambientais de forma limpa e lucrativa.

Diante deste fato buscaram-se alternativas para o desenvolvimento de novos produtos que comprometam a utilização total ou parcial dos resíduos orgânicos gerados na indústria, reduzindo impactos ambientais e agregando completo valor nutricional ao produto final com baixo custo de comercialização. Dentre as alternativas propostas destaca-se a utilização do resíduo da laranja e do mamão como matéria primas para produção de ração animal.

Na literatura poucos estudos relatam sobre o emprego de coprodutos na alimentação para animais, tornando-se necessárias investigações a respeito. A correta utilização das matérias primas nas formulações de dietas para cães e gatos depende do conhecimento dos seus benefícios, assim, sendo necessários estudos que avaliem a composição química, a disponibilidade dos nutrientes e efeito no metabolismo animal (Abud e Narain, 2009).

O objetivo deste trabalho consistiu em elaborar um fluxograma de processo e avaliar o processo de produção de ração animal a partir da simulação computacional visando o reaproveitamento da biomassa proveniente do processo de frutas cristalizadas. De acordo com os dados fornecidos pela indústria em estudo (localizada no Município de Três Rios/RJ) processam-se cerca de 5.000 toneladas de frutas cristalizadas por ano. Deste valor, $15 \%$ são perdas gerando aproximadamente 750 toneladas de resíduos de polpa de mamão com semente e 750 toneladas de polpa de laranja anuais, uma média de 2 toneladas por dia de cada resíduo. Por isso, destaca-se a possibilidade da instalação de uma nova planta para o processamento de ração animal ao final do processo produtivo da indústria.

\section{MATERIAIS E MÉTODOS}

Para um melhor embasamento tanto para o conhecimento do processo e do resíduo de frutas proposto, uma busca pela legislação vigente foi realizada, sendo ela identificada como: Portaria $n^{\text {o: }}$ 3, de 22 janeiro de 2009 do Ministério da Agricultura, Pecuária e Abastecimento (MAPA), onde determina os critérios e os procedimentos para o registro de estabelecimentos e produtos, para a rotulagem e a propaganda e para a isenção de registro de produtos destinados à alimentação de animais de companhia. Alguns dados desta legislação, podem ser visualizados conforme a Tabela 1 . 


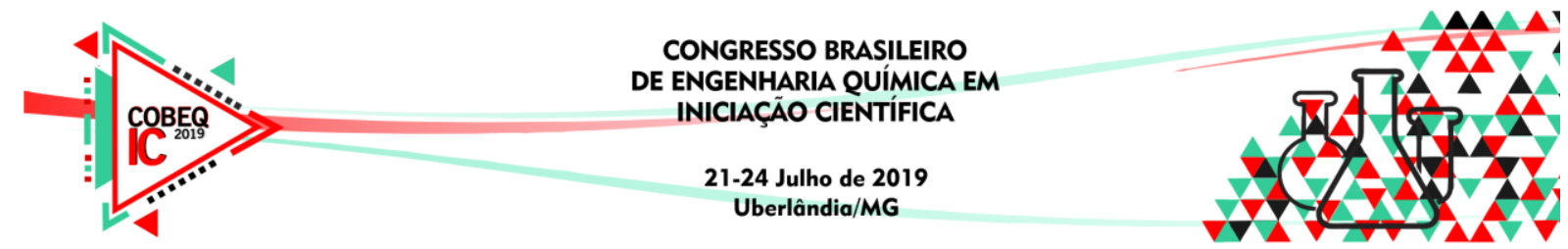

Tabela 1 - Limites de níveis de garantia estabelecidos pela legislação vigente

\begin{tabular}{|c|c|c|}
\hline Parâmetro & Limite & Valor para ração destinada a cães adultos (\%) \\
\hline \hline Umidade & Máximo & 12,0 \\
\hline Proteína Bruta & Mínimo & 16,0 \\
\hline Gordura (extrato etéreo) & Mínimo & 4,5 \\
\hline Matéria Mineral & Máximo & 12,0 \\
\hline Atributo & Limite & $3.100^{*}$ \\
\hline \hline \multirow{2}{*}{ Valor Calórico } & Máximo & $900^{* *}$ \\
\cline { 2 - 3 } & Máximo & Valor Calórico (Kg) \\
\hline
\end{tabular}

* Para alimentos formulados com até $12 \%$ de umidade ** Para alimentos com mais de $65 \%$ de umidade. Fonte: BRASIL, 2009 (Adaptada).

Para posterior comparação com a legislação vigente e inserção no sistema do software utilizado na simulação do processo, análises foram realizadas em um laboratório credenciado, seguindo as Normas Analíticas do Instituto Adolfo Lutz (Métodos físico-químicos para análise de alimentos) e AOAC Official Methods of Analysis. Estes valores foram utilizados na corrente de alimentação e podem ser visualizados de acordo com a Tabela 2, bem como o fluxograma do processo de produção de ração desenvolvido no simulador de processos SuperPro Designer ${ }^{\circledR}$ é ilustrado na Figura 1.

Tabela 2 - Composição do resíduo de laranja e mamão

\begin{tabular}{|c|c|c|}
\hline Parâmetro $(\mathbf{g} / \mathbf{1 0 0 g})$ & Polpa de mamão com semente & Polpa de laranja \\
\hline \hline Umidade & 74,73 & 86,15 \\
\hline Proteína Bruta & 1,64 & 1,37 \\
\hline Gordura & 0,3 & 0,3 \\
\hline Matéria Mineral & 11,7 & 0,48 \\
\hline Carboidrato & 11,63 & 11,7 \\
\hline Valor Calórico $(\mathrm{Kcal} / \mathrm{kg})$ & 552,8 & 505,1 \\
\hline
\end{tabular}

Figura 1 - Processo de ração animal no simulador de processos SuperPro Designer ${ }^{\circledR}$.

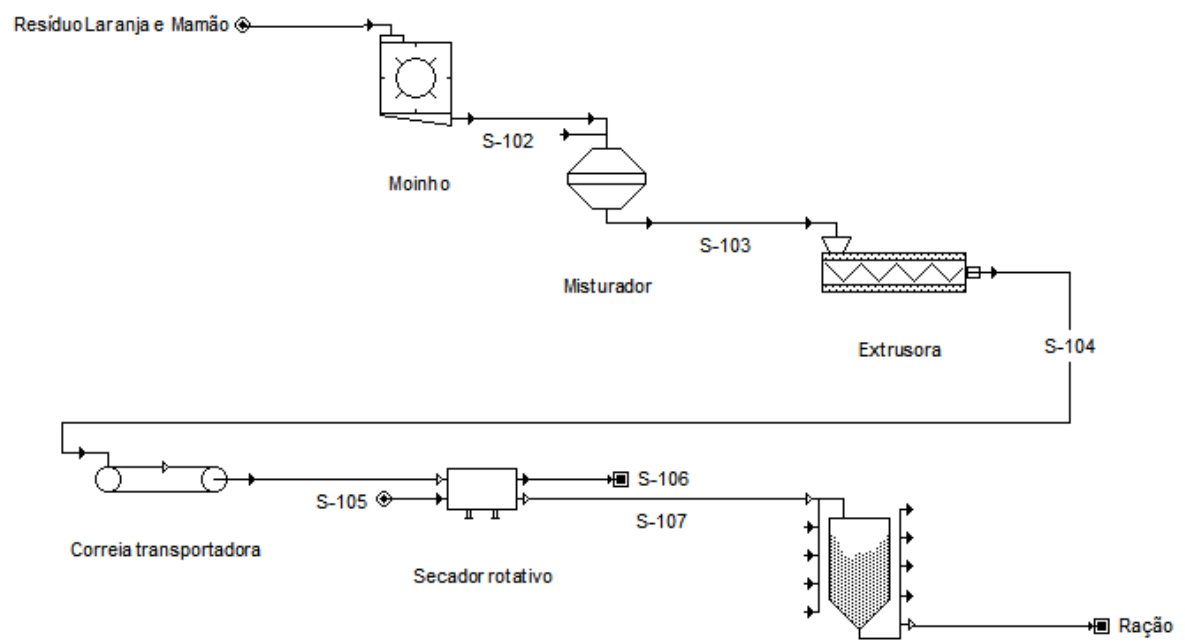




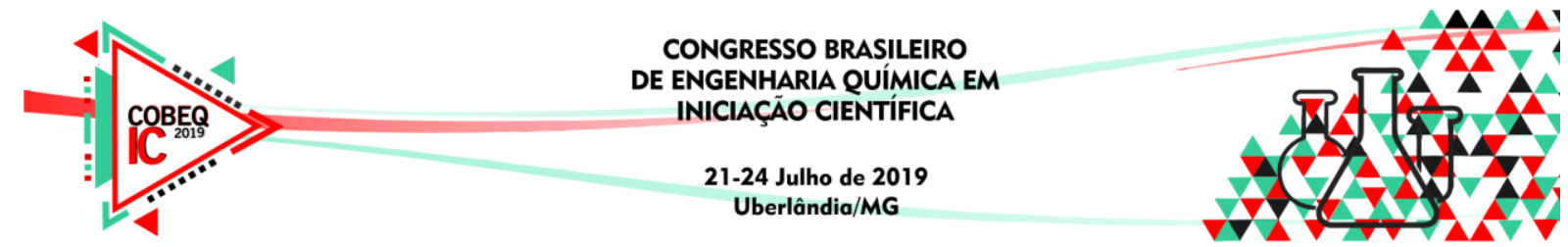

Para início do processo, o moinho tem como objetivo triturar a biomassa com os outros componentes que produzirá a ração. Esses componentes precisam ser triturados, pois tem granulometrias diferentes uns dos outros.

A extrusora pode ser trabalhada com diferentes tipos de formas de ração de acordo com o tipo e raça do animal, havendo possibilidade da troca de placas em caso de ajuste de algum parâmetro. $\mathrm{Na}$ extrusora ocorre aquecimento, não podendo chegar a $100^{\circ} \mathrm{C}$ pois poderá desativar algumas enzimas de acordo com a matéria prima utilizada.

A correia transportadora foi empregada na simulação para transportar o material até o secador rotativo, e também, entrar em contato com a temperatura ambiente para que a ração tenha um aspecto crocante.

O processo de secagem rotativa foi utilizado para a obtenção de uma umidade final, e também onde é normalmente num processo de ração adicionados gordura e flavorizantes para que os animais se interessem em comer a ração. Posteriormente este produto fica armazenado em um silo sendo disponível para empacotamento ou expedição a granel.

A composição da alimentação do processo de simulação da ração foi de $10 \%$ de polpa de mamão com semente e $10 \%$ de polpa de laranja, $80 \%$ são considerados outros insumos (representa todos os outros compostos e suas respectivas quantidades que serão necessárias para adição, como: grãos de milho, cerais, farinha de vísceras de frango e outros) a serem inseridos de acordo com a composição desejada. A massa de alimentação é de 20 toneladas por batelada, sendo assim, 4 toneladas de biomassas (mamão e laranja) e 16 toneladas de insumos por batelada. O processo foi estudado para que as frações de biomassa entrassem como parte da ração e seus insumos.

\section{RESULTADOS E DISCUSSÃO}

Para a comparação do balanço de massa global, utilizaram-se os dados dos componentes da entrada do processo e saída e com os parâmetros de vazão e massa do componente. Estes dados podem ser visualizados conforme as Tabelas 3 e 4 .

Tabela 3 -Componentes de entrada desenvolvidos pelo software.

\begin{tabular}{|c|c|c|}
\hline Componente & Vazão (kg/batelada) & Massa do componente (\%) \\
\hline \hline Umidade & 3234,6 & 16,173 \\
\hline Proteína Bruta & 54,8 & 0,274 \\
\hline Gordura & 10 & 0,05 \\
\hline Matéria Mineral & 242 & 1,21 \\
\hline Carboidrato & 458,6 & 2,293 \\
\hline Outros insumos & 16000 & 80 \\
\hline
\end{tabular}




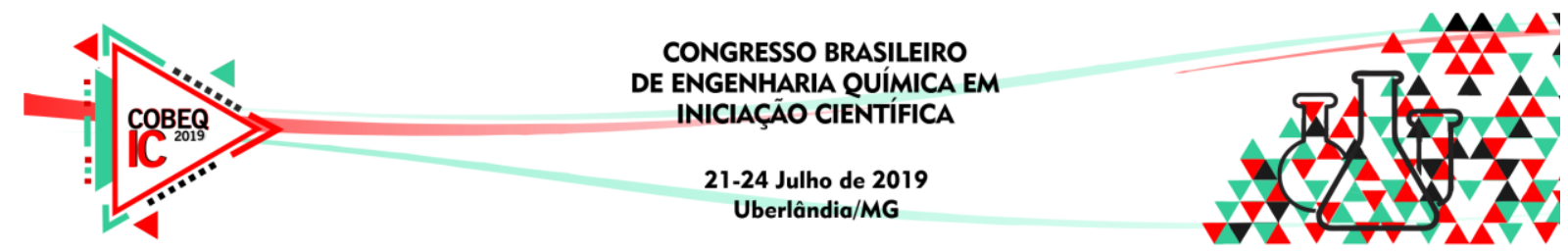

Tabela 4 - Componentes de saída desenvolvidos pelo software.

\begin{tabular}{|c|c|c|}
\hline Componente & Vazão (kg/batelada) & Massa do componente (\%) \\
\hline \hline Umidade & 2286,19 & 12 \\
\hline Proteína Bruta & 54,8 & 0,2876 \\
\hline Gordura & 10 & 0,0525 \\
\hline Matéria Mineral & 242 & 1,27 \\
\hline Carboidrato & 458,6 & 2,4071 \\
\hline Outros insumos & 16000 & 83,9825 \\
\hline
\end{tabular}

Comparando as análises efetuadas da Tabela 2 com os limites estabelecidos pela legislação vigente na Tabela 1, constata-se um alto nível de umidade, e um possível problema a ser resolvido durante o processo do subproduto. Entretanto, há uma perda significativa de umidade no produto que segue os parâmetros propostos pela legislação. Essa perda ocorre na operação unitária de secagem.

Em relação aos limites mínimos, tem-se proteína bruta e gordura, que demonstram a necessidade de adição de outros insumos para atender à Portaria de base. Verifica-se também os parâmetros matéria mineral e valor calórico, dentro dos limites estabelecidos, apesar da polpa de mamão com semente estar muito próxima deste valor em relação à matéria mineral.

Analisando as Tabelas 3 e 4, verifica-se a massa total de entrada é de $20.000 \mathrm{~kg}$ e a massa total de saída é equivalente a $19051,59 \mathrm{~kg}(948,41 \mathrm{~kg}$ de água consumida). Os demais componentes alteram valores da porcentagem da massa do componente devido à secagem do produto onde, houve perda de umidade então há aumento de nutrientes na massa seca.

Considerando que nem todos os parâmetros estabelecidos pela legislação foram analisados e tendo em vista que para que o produto final possa ser comercializado um ajuste nos valores encontrados deverá ser feito, visando adicionar ou retirar (no caso de umidade por exemplo) compostos. Em uma verificação de composição da ração para cães adultos da marca Pedigree $^{\circledR}$ sem o aprofundamento das proporções, pode-se observar que ingredientes como: farinhas de subprodutos de frango e ossos, gordura, farelos, vitaminas, minerais, entre outros, poderão ser adicionados a fim de obter os ajustes necessários conforme mencionado anteriormente. Destaca-se ainda, grande parte dos nutrientes contidos na ração pesquisada, já são encontrados na biomassa proposta neste trabalho.

\section{CONCLUSÃO}

De acordo com a capacidade estabelecida da alimentação do processo e a análise comparativa dos parâmetros da biomassa com a legislação, consta que o uso da biomassa no processo de ração para cães é satisfatória e sustentável, apesar de suprir somente uma fração dos nutrientes, a biomassa substitui uma parte do material que seria gasto e possui umidade para o cozimento gerando economia. E ainda reutiliza resíduos que seriam descartados e que gerariam impactos ao meio ambiente. 


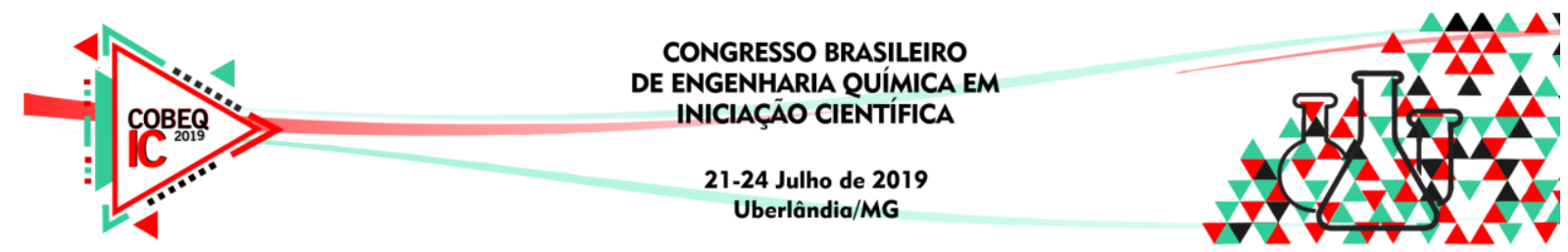

Alguns ajustes deverão ser realizados a fim de estabelecer produto final de acordo com a composição especificada na Tabela 1 . Assim, fornecendo qualidade ao produto e verificação completa da norma vigente.

\section{REFERÊNCIAS}

ABINPET. Mercado. Disponível em: <http://abinpet.org.br/mercado/>. Acesso em: 12 abr. 2019.

ABUD, A.K.S.; NARAIN, N. Incorporação da farinha de resíduo do processamento de polpa de fruta em biscoitos: uma alternativa de combate ao desperdício. Sergipe, 2009. Disponível em: <http://bj.ital.sp.gov.br/artigos/html/busca/PDF/v12n4389a.pdf>. Acesso em: 12 abr. 2019.

BRASIL. Ministério da Agricultura, Pecuária e Abastecimento. Portaria no 3, de 22 de janeiro de 2009. Estabelece os critérios e os procedimentos para o registro de estabelecimentos e produtos, para a rotulagem e a propaganda e para a isenção de registro de produtos destinados à alimentação de animais de companhia. Diário Oficial [da República Federativa do Brasil], Brasília, 23 de janeiro de 2009.

LIRIO, F. R.; RIGATTI, L.F.; VARGAS, J.V.C. Estudo energético de um processo industrial para a produção de ração animal com aplicação da biomassa de microalga como aditivo nutricional. Gestão, Tecnologia e Inovação, Curitiba - PR, v. 2, n. 1, p. 26-35, jan./abr. 2018.

PEDIGREE $^{\circledR}$. Pedigree ${ }^{\circledR}$ adulto carne, frango \& cereais. Disponível em: $<$ https://www.pedigree.com.br/produtos/adultos/pedigree-adulto-carne-frango-andcereais>. Acesso em: 02 abr. 2019.

SOUZA, M. S. B.; et al. Caracterização nutricional e compostos antioxidantes em resíduos de polpas de frutas tropicais. Teresina, 2011. 